\title{
LAS ÓRDENES MILITARES \\ EN LA CRUZADA GRANADINA DE ALFONSO EL BENIGNO
}

(1329-1334)

\author{
MANUEl SÁNCHEZ MARTÍNEZ \\ Institución Milá y Fontanals \\ (CSIC Barcelona)
}

\begin{abstract}
SUMARIO
1. Introducción. 2. La Orden del Hospital. 3. Làs otras Órdenes: A) La Orden de Montesa; B) La Orden de Calatrava (encomienda de Alcañiz); C) La Orden de Santiago (encomienda de Montalbán). 3. Consideraciones finales
\end{abstract}

\section{INTRODUCCIÓN}

Hace ya un cuarto de siglo, cuando realizaba mi tesis doctoral dedicada a la expedición granadina de Alfonso el Benigno, puse al frente del capítulo que trataba de la participación de las Órdenes en la cruzada el título de Una abstención significativa: las Órdenes militares. En rigor, no hubo tan drástica ni genérica abstención: veremos cómo algunos freires hicieron su correspondiente servicio fronterizo e incluso tomaron parte activa en alguna fugaz entrada en tierras nazaríes. Ahora bien, como dicha participación fue siempre discutida, regateada - cuando no abiertamente rechazada-, y aceptada in extremis después de severas amenazas por parte del monarca, me pareció entonces que abstención era un vocablo que cuadraba bien para caracterizar el clima general de la actuación de las Órdenes en la cruzada de Alfonso el Benigno. Que considerase significativo ese comportamiento

"Anuario de Estudios Medievales". 28 (1998) 
tampoco requiere demasiadas explicaciones: si las Órdenes, fundadas con el exclusivo propósito de luchar contra el Islam, no acudían en masa y sin reservas a la defensa de la frontera, ¿podía pedirse más entusiasmo, pongamos por caso, a un noble laico de Cataluña o de Aragón o a la milicia de cualquier universidad valenciana? El propio monarca, que había concebido y preparado su expedición a la usanza - ya anacrónica- de una cruzada tradicional, fue el primer sorprendido cuando los freires daban excusas para él incomprensibles, tratándose de un ejército - son las propias palabras emanadas de la cancillería real- basado en la disciplina militar y nacido para desempeñar una función muy específica: la protección de los cristianos que habitaban en los confines con el Islam. Veremos además que, cuando más peligrosas y ciertas eran las amenazas de los nazaríes en la zona fronteriza, el rey sólo confiaba, por encima de otros medios defensivos, en el presuntamente eficaz servicio de las Órdenes.

Veinticinco años después de la realización de mi tesis, he creído oportuno volver a aquellas viejas páginas para no apartarme ni un ápice del tema de investigación que cultivaba Regina Sainz de la Maza, la entrañable compañera desaparecida: las Órdenes militares catalanoaragonesas durante el s. XIV. Si bien no he realizado una nueva pesquisa en el Archivo de la Corona de Aragón, sí he vuelto a leer la documentación utilizada entonces y, en la medida de lo posible, he procurado actualizar la bibliografía'.

Creo que el posible interés del trabajo radica en el hecho de que en él se considera, de manera conjunta, la actuación en la cruzada de las cuatro Órdenes militares enclavadas en territorio catalanoaragonés, lo cual permite observar tanto su distinto grado de participación como la diferente actitud del monarca hacia cada una de ellas. Ahora bien, los datos que aporto sólo son simples pistas, que no aclaran del todo las razones profundas - más allá de las meras generalidades- de tales comportamientos. Dicho más concretamente, no me será posible explicar, por ejemplo, las causas de la asistencia puntual e incontrovertida de la Orden de Montesa a la frontera, los motivos específicos de la reiterada resistencia al servicio por parte de la Orden hospitalaria y, dentro de ella, de la castellanía de Amposta; ni tampoco

\footnotetext{
'Debo agradecer a la Dra. María Bonet Donato, estudiosa de la Orden hospitalaria en la Corona de Aragón, su amable lectura crítica de mi viejo texto y su generosidad a la hora de proporcionarme valiosas sugerencias. Aunque naturalmente las deficiencias del trabajo sólo a mí son imputables. tengo especial interés en subrayar que, sin el estímulo de la Dra. Bonet, estas páginas nunca hubiesen visto la luz.
} 
podré dar una respuesta satisfactoria a porqué las Órdenes de Calatrava y Santiago estuvieron prácticamente ausentes de la zona fronteriza y experimentaron en mucho menor grado que el Hospital las duras medidas adoptadas por la monarquía. No siendo especialista en este tema concreto, y ante lo poco que sabemos todavía sobre cada encomienda en la coyuntura precisa del primer tercio del s. XIV, me voy a limitar a exponer descarnadamente los datos documentales a la espera de que sean valorados e interpretados en sus justos límites por los estudiosos de las Órdenes militares.

En cualquier caso, más allá de la evidente crisis del espíritu cruzado en unas Órdenes mucho más preocupadas por la gestión rentista -y absentista - de sus patrimonios, hemos de reconocer que las reticencias a participar en la campaña granadina o el hecho de acudir a la frontera sin el entusiasmo que el rey esperaba hunden sus raíces en las mismas entrañas de ese acontecimiento. Es de sobra sabido que la aparatosa cruzada imaginada por Alfonso el Benigno - verdadero leit-motiv de su reinado y generadora de una copiosa masa documental - fue un completo fracaso. Ni la ofensiva por tierra superó nunca el nivel de la simple algara fronteriza ni la armada catalanoaragonesa logró evitar la caída de Gibraltar en 1333. Los sucesivos aplazamientos de la entrada personal del rey en tierras nazaríes, las continuas vacilaciones del Benigno, los indecisos avances de los contingentes armados (tan pronto urgentemente movilizados como dispensados a continuación del servicio) y las frecuentes contradicciones en la táctica a emplear jalonaron los cinco años de intensa preparación de la campaña. En mi viejo estudio puse en relación la frustración global de la empresa con el fracaso de todos y cada uno de los medios materiales y humanos (dinero, hombres, navíos, sistemas defensivos, etc.) pulsados por el monarca para llevarla a cabo, precisamente en aquellos críticos años ${ }^{2}$. Por tanto, la escasa predisposición de los freires a realizar el servicio adquiere otro sentido si se pone en íntima relación con el desarrollo de un acontecimiento condenado al fracaso desde el principio.

Dado que la documentación referente a los hospitalarios es mucho más abundante que la conservada para el resto de las Órdenes, examinaré en primer lugar aquel caso, procurando insertar los datos obtenidos en el relato general de la expedición granadina. Para los casos de Montesa, Calatrava y

\footnotetext{
${ }^{2}$ Cf. M. SÁnChez Martínez, La Corona de Aragón y el reino nazarí de Granada durante el s.XIV: las bases materiales y humanas de la cruzada de Alfonso IV (1329-1335), resumen de tesis doctoral, Barcelona, 1983.
} 
Santiago, bastará con marcar los rasgos más sobresalientes de su actuación en la cruzada sin necesidad de volver de nuevo al hilo de los acontecimientos.

\section{LA ORDEN DEL HOSPITAL}

Recordemos que, en febrero de 1329, Alfonso el Benigno y Alfonso XI de Castilla firmaban en Tarazona una alianza para hacer la guerra a Muhammad IV de Granada ${ }^{3}$. En consecuencia, durante la primavera de aquel año, se procedió al acondicionamiento de la zona fronteriza y se cursaron las primeras convocatorias a los caballeros y mesnaderos aragoneses, a los feudatarios catalanes y a las milicias urbanas ${ }^{4}$. Y, naturalmente, también a las Órdenes militares: a mediados de marzo, el rey se dirigía a Sancho de Aragón (castellán de Amposta), a Arnau d'Alós (prior de Cataluña), a Pere de Tous (maestre de Montesa), a Garci López (maestre de Calatrava) y a Vidal de Vilanova (comendador de Montalbán) para notificarles los pactos de Tarazona y ordenarles que estuviesen preparados para cumplir el servicio de frontera ${ }^{5}$. A este simple aviso sucedió otra carta, a finales de abril, donde se concretaba la fecha de incorporación - a lo largo del mes de mayo-, se precisaba el lugar del servicio - Orihuela- y se fijaba el número de contingentes: el castellán debía acudir con 50 caballos y el prior con $40^{6}$. Es más que probable que este primer servicio exigido a las Órdenes en la cruzada granadina no fuese cumplido; y ello no tanto por negligencia de los freires sino por los propios problemas fronterizos en la primavera de 1329 y el deliberado deseo del rey de no efectuar incursiones,

\footnotetext{
${ }^{3}$ Véase M. SÁNCHEZ, Guerra, avituallamiento del ejército y carestías en la Corona de Aragón: la provisión de cereal para la expedición granadina de Alfonso el Benigno (1329-1333), "Historia. Instituciones. Documentos", XX (1993), p. 524, nota 2 (con las oportunas referencias bibliográficas).

${ }^{4}$ Cf. M. SÁnchez, La Corona de Aragón y Granada, tesis doctoral, Barcelona, 1974, II, pp. $701-720$

${ }^{5} \mathrm{ACA}, \mathrm{C}, \mathrm{Cr}$., Alfons III, $\mathrm{n}^{0} 2147$ y reg. 539, fol. 38r.; en adelante, suprimiré la referencia al Archivo, pues toda la documentación utilizada procede del de la Corona de Aragón.

${ }^{6} \mathrm{C}$, reg. 539, fol. 38v. Con la misma fecha, el rey escribía al maestre del Hospital, Helio de Villanueva, para que ordenase al castellán y al prior acudir a la frontera; Ibídem, fol. $39 \mathrm{r}$.
} 
por el momento, en territorio nazarí ${ }^{7}$ Pero, en el mes de julio, el adelantado castellano Pero López de Ayala alertaba al rey de Aragón de la presencia de tropas nazaríes y le solicitaba el rápido envío de combatientes; inmediatamente, el Benigno mostró su intención de acudir en persona a la frontera al tiempo que ordenaba a todas las Órdenes de la Corona reunirse con él en Xàtiva el 8 de agosto. Aunque el 9 de este mes, el rey dispensaba el servicio personal del castellán y del prior, veremos enseguida cómo, por lo menos, tres comendadores hospitalarios estaban en Orihuela a mediados de agosto ${ }^{8}$.

Así pues, el año 1329 transcurrió sin que sucediese ningún acontecimiento relevante en las dos fronteras - la castellana y la catalanoaragonesa-, pero, tanto Alfonso XI (Cortes de Madrid) como Alfonso el Benigno (Cortes de Valencia) dispusieron todo lo necesario para hacer su entrada personal en el sultanato en mayo de 1330; en este mismo sentido, en noviembre de 1329, a través de la embajada a Castilla de Martín Íñiguez de Eslava, quedó perfilado el plan de invasión conjunta del reino nazarí ${ }^{9}$. Pero, cuando más intensos eran los preparativos, a mediados de marzo se supo con certeza que la cruzada catalanoaragonesa quedaba aplazada hasta abril de 1331. Ya a finales de febrero de 1330, el Benigno había expresado a los embajadores de Castilla y Portugal, cuando éstos regresaban de Aviñón, hasta qué punto la gravedad de la situación sarda le impedía emprender personalmente la expedición contra Granada; no obstante, para ayudar a

\footnotetext{
${ }^{7}$ Es posible que el corto espacio de tiempo transcurrido desde los pactos de Tarazona sorprendiese al monarca sin los medios materiales y humanos necesarios para penetrar en el reino de Granada; por ejemplo, a mediados de abril, el Benigno prohibía al procurador Jofre Gilabert de Cruilles hacer entradas en terra de moros hasta recibir nuevo aviso; C, reg. 531, fols. 105v.-106v.; véase $\mathrm{M}^{\mathrm{a}}$ T. FERRER MALLOL, La frontera amb l'Islam en el segle XIV Barcelona, 1988, p. 126. Sobre algunos problemas fronterizos en la primavera de 1329 , véase M. MARTÍNEZ-M. SÁNCHEZ, El reino de Murcia en la alianza castellano-aragonesa contra el sultanato nazarí (1329), "IV Jornades Luso-Espanholas de História Medieval”, Porto, 1997, en prensa.

${ }^{8}$ C, reg. 541, fol. 23r.; cf. A. GimÉnEz SOLER, La Corona de Aragón y Granada, "Boletín de la Real Academia de Buenas Letras de Barcelona”, IV (1907-1908), pp. 161-162. A la cita de Xàtiva el castellán debía acudir con 50 caballos, el prior con 40, el maestre de Montesa con 60 (?), el de Calatrava con 15 y el comendador de Montalbán con 20; C, reg. 539, fols. 39v.40r. y Cr. Alfons III, $n^{\circ} 3426$. 548.

${ }^{9} \mathrm{C}$, reg. 562, fols. 114r.-116v., documento transcrito por M. SÁNCHEZ, Guerra, pp. 546-
} 
Alfonso XI, había ordenado el armamento de diez galeras y dispuesto el envío, entre otros combatientes, de las Órdenes militares ${ }^{10}$.

Muy pronto empezaron los problemas por lo que respecta al servicio de los hospitalarios. Como he apuntado más arriba, tres comendadores de la Orden estaban a mediados de agosto de 1329 en Orihuela; desde allí escribieron al monarca para que se encargara de disculparlos ante el maestre Helio de Villanueva por su incomparecencia a la cita que éste les había dado en Aviñón ${ }^{11}$. Probablemente debieron continuar las fricciones al respecto pues, meses después, el Benigno transmitía al maestre la petición de los tres comendadores citados, ponderándole la importancia del servicio que realizaban $^{12}$; al parecer, Villanueva insistió en convocarlos a Aviñón sub virtute sancte obedientie, pero el rey se mantuvo firme en su propósito de no dejarlos abandonar la frontera ${ }^{13}$. En este primer choque con la Orden del Hospital a raiz de la cruzada granadina se refleja perfectamente el conflicto derivado de la duplicidad de jurisdicciones: la "internacional" representada por el maestre y la que pretendía ejercer el monarca sobre las encomiendas situadas en el territorio de la Corona, criterio que parece triunfar aquí ${ }^{14}$.

${ }^{10}$ Véase J. ZuriTA, Anales de la Corona de Aragón, Lib. VII, Cap. XI, ed. A. Canellas, vol. 3, Zaragoza, 1978, p. 334; además de las Órdenes, en abril-mayo fue movilizada una compañía al mando del vizconde de Cabrera: C, reg. 54l, fols. 50r.-v. y 55r. No voy a entrar en las causas de este primer aplazamiento de la cruzada, que me llevaría muy lejos del objetivo de estas páginas; véase M. SÁnchEZ, Guerra, pp. 529-531.

"Se trata de Lope de Luna, comendador de Mallén; Alonso Fernández Garín, comendador de Castellot y Sancho Rodríguez de Valtierra, comendador de Castilíscar; quizás estos tres nombres permitan completar las listas de comendadores dadas por J. MIRET I SANS, Les cases de Templers $i$ Hospitalers en Catalunya, Barcelona, 1910, p. 531 y por A. LUTTRELL, The Structure of the Aragonese Hospital: 1349-1352, "Actes de les primeres Jornades sobre els Ordes religioso-militars als Països Catalans (segles XII-XIX)", Tarragona, 1994, pp. 324-328. Los comendadores, conscientes de lo que suponía el incumplimiento de la llamada del maestre, le decían al rey: "bien sabedes el periglo en que nos estamos con el maestro nuestro del Espital por complir el vuestro mandamiento", esto es, la orden de acudir a la frontera; Cr., Alfons III. no 3426 (la carta no indica el año, pero debe tratarse de 1329)

${ }^{12} \mathrm{C}$, reg. 541, fols. 46v.-47r., cit. por A. LuTTRELl, The Aragonese Crown and the Knights Hospitallers of Rhodes: 1291-1350, "The English Historical Review”, CCXCVIII (1961), p. 9, nota 3; a los comendadores citados se añadía ahora el de Guillermo de Anguera, de la casa de Calatayud.

${ }^{13} \mathrm{C}$, reg. 541 , fol. $43 \mathrm{r}$.

${ }^{14}$ Cf. M. Bonet Donato, La Orden del Hospital en la Corona de Aragón. Poder y gobierno en la castellanía de Amposta (ss.XII-XV), Madrid, 1994, p. 67. A pesar de la gravedad de éste y de otros contenciosos, la profunda alianza entre la monarquía y el castellán, derivada de la comunidad de unos intereses centrados en la propia Corona catalanoaragonesa, acabaría por prevalecer; cf. LUTTRELL, The Aragonese Crown, p. 18. 
Dejando al margen el litigio que, hacia marzo de 1330, enfrentaba al castellán con Pere de Tous, maestre de Montesa, y que también obstaculizaba la participación de ambas Órdenes en la cruzada ${ }^{15}$, el siguiente choque del monarca con la castellanía se produciría en la primavera de 1330. Aunque no he localizado el documento en cuestión, el castellán y otros freires de las Órdenes debieron ser convocados para hacer el servicio fronterizo por aquellos dias ${ }^{16}$. Pero, a la altura del 19 de mayo, Sancho de Aragón no había acudido con la excusa de no disponer por el momento del dinero necesario para prepararse él mismo y su comitiva; el Benigno le urgió a ponerse inmediatamente en camino $\mathrm{y}$, para que no pudiese aducir problemas monetarios, le prohibió que pagase al maestre los correspondientes tributos regulares (responsiones) y los emplease en el viaje a la frontera ${ }^{17}$. En este mismo sentido, el rey ordenó a Bonifacio de Saluces, comendador de Monzón, que la responsio íntegra la pagase al castellán y no al maestre, con el fin de facilitar el servicio fronterizo de Sancho de Aragón ${ }^{18}$. Quizás se deba inscribir en este tenso ambiente la expulsión de

\footnotetext{
${ }^{15}$ El rey habia convocado al castellán y al maestre para discutir cuestiones referentes a la guerra de Granada pero, antes, deberían cesar sus mutuas disensiones; aunque se silencia la causa del enfrentamiento, no parece arriesgado pensar que se debiese a conflictos jurisdiccionales: C, reg. 541, fol. 43r., cit. LUTTRELL, The Aragonese Crown. p. 9. nota 3.

${ }^{16}$ Según Zurita, fueron enviados a la frontera el maestre de Montesa, el castellán y los comendadores de Montalbán y Alcañiz..." y fuéronse a poner en Orihuela, en fin del mes de abril para pasar a la villa de Lorca y hacer de allí su entrada" (ZURITA, Ancles, Lib. VII, Cap. XI, p. 334 de la ed. citada)

${ }^{17} \mathrm{C}$, reg. 541 , fol. $54 \mathrm{v}$.; carta parcialmente transcrita por GIMÉNEZ SOLER , op. cit., p.246 y citada por LUTTRELL, The Aragonese Crown, p. 9, nota 3. Recordemos que, ya a finales de 1329, el Benigno pedía al papa su intercesión ante el maestre del Hospital para que, mientras durase la guerra de Granada, las responsiones de la castellanía y del priorato se invirtiesen en la expedición; al mismo tiempo, se solicitaba una reducción de los respectivos tributos: una vez finalizada la guerra, el castellán pagaría como responsio 2.500 florines y el priorato 2.000; C, reg. 522, fol. 229r.; cf. LUTTRELL, art.cit., p. 10, nota 1 y The Structure, p. 317 y Hospitaller life in Aragon: 1319-1370, en God and Man in Medieval Spain. Essays in honour of J.R.L. Highfield, ed. by D.W. Lomax and D. Mackenzie, Warminster, 1989, p. 113. Véase el excelente capítulo consagrado a la fiscalidad sanjuanista por M. BONET. op .cit. . pp. 156-177; recogiendo noticias de Waldstein-Wartenberg, esta autora apunta que, en el s.XIV, las responsiones equivalían a una cuarta o quinta parte de los ingresos de cada encomienda. Por su lado, LUTTRELL, The Structure of the Aragonese Hospital, p. 317, después de admitir la dificultad de saber la parte de los ingresos de cada encomienda que se pagaba como responsio, calcula que, si las rentas anuales de la castellanía entre 1319 y 1324 ascendían a unos 332.000 sj., la suma de $28.000 \mathrm{sj}$. a que el rey deseaba fijar la responsio en 1329 supondría poco más del $8 \%$ de aquellos ingresos.

${ }^{18}$ Se mandaba a Saluces revocar las dites ya hechas a mercaderes para abonar la responsio al maestre (C, reg. 541, fol. 54r.); es sabido que las redes comerciales mediterráneas fueron utilizadas para vehicular los pagos a Rodas; cf. BONET, op. cit., pp. 174-177. Pero, en esta
} 
Jofre Rostany, visitador de la Orden, decretada a finales de mayo por el monarca debido a que perturbaba la campaña granadina ${ }^{19}$. Sabemos que, a comienzos de junio de 1330 , el Benigno se dirigía a los oficiales de la Corona para que el castellán y el prior fuesen acogidos favorablemente en los territorios fronterizos hacia donde se encaminaban ${ }^{20}$. Ignoro si Sancho de Aragón realizó el servicio requerido; por lo que respecta al prior de Cataluña, parece que protagonizó, en compañía de Jofre Gilabert, Pere de Tous (maestre de Montesa), don Juan Manuel y el obispo de Murcia, una importante incursión en la frontera oriental nazarí durante la última semana de agosto de $1330^{21}$.

Así pues, si el rey de Castilla había llevado a cabo una provechosa campaña en la frontera andaluza ${ }^{22}$, el Benigno no se había movido de territorio catalanoaragonés, limitándose a contribuir en la guerra con el refuerzo de cinco galeras y el envío de ciertos contingentes armados. Sin embargo, se preparaba con gran despliegue de medios (convocatorias a los feudatarios y a las milicias urbanas; peticiones masivas de subsidios;

ocasión, el rey tuvo que dar marcha atrás: es probable que la responsio de la encomienda de Monzón ya estuviese obligada a mercaderes, por lo que el Benigno hubo de permitir que, solamente por esta vez, aquella se abonase a quién correspondiese; C, reg. 541, fol. 57r.

${ }^{19} \mathrm{C}$, reg. 541, fol. 54r., transcrita por GiménEZ SOLER, op. cit., p. 167 y cit. por LutTRELl, The Aragonese Crown, p. 7, nota 10.

${ }^{20} \mathrm{C}$, reg. 541, fol. 56r. Pocos dias antes, y dada su avanzada edad, se eximía el servicio personal de Guillem Rabaça, comendador de Barbastro, mientras se le exigía perentoriamente al de Monzón; reg. 541, fol. 54v., cit. por LutTRELl, The Aragonese Crown, p. 9, nota 3.

${ }^{21}$ Conocemos esta algara gracias a un largo y detallado documento transcrito (sin indicación de cota) por A. GIMÉNEZ SOLER, Don Juan Manuel. Biografía y estudio crítico, Zaragoza, 1932, doc. 488, pp. 582-584. Dividido en dos cuerpos de ejército, el grupo dirigido por don Juan Manuel, el obispo de Murcia, el prior de Cataluña y el maestre de Montesa talaron las huertas de Huércal, Zurgena y Arboleas y, unido ya al que comandaba Jofre Gilabert, saquearon los alrededores de Albox, Overa, Vera y Cuevas de Almanzora. El documento es una perfecta descripción de una típica incursión fronteriza, donde no falta ningún ingrediente: la tala de las huertas, la destrucción de las atalayas, el saqueo de los poblados, las celadas dejadas en ciertos lugares, algún que otro episodio de perfume caballeresco (por ejemplo, la celebración de torneos con jinetes musulmanes en las proximidades de Vera) y la sistemática negativa a combatir los castillos. Pero, por encima de otros detalles, el documento muestra perfectamente la miseria de la guerra fronteriza, nunca planteada en torno a la conquista de una plaza fortificada sino basada en el saqueo, el pillaje, la muerte de campesinos y la destrucción de sus débiles haciendas, sin que la operación reportase a los invasores algo más que un débil botín y, desde luego, ninguna ventaja militar. La participación del prior de Cataluña y del maestre de Montesa en esta algara puede deducirse de una carta de Bernat de Sarrià al rey $(\mathrm{C}, \mathrm{Cr}$. Alfons III, n“ 1272) y del mismo GIMÉNEZ SOLER, op. cit., pp. 97-98.

22Después de un largo asedio, Teba cayó en poder de Alfonso XI en agosto de 1330 y, poco después, Cañete la Real, Las Cuevas y Ortegícar; cf. M. GARCía FERNÁnDEZ, Andalucía en tiempos de Alfonso XI, tesis doctoral en microfichas, Universidad de Sevilla, 1987, pp. 50-51. 
preparación meticulosa del armamento y del aprovisionamiento del ejército; activación de los hilos diplomáticos con Aviñón y diversas cortes europeas, etc.) para su próxima $-y$, al parecer, ya improrrogable - entrada en tierras nazaríes a finales de marzo de 1331. Toda la intensa actividad de la cancillería durante el otoño e invierno de 1330 iría encaminada a ese fin. Pero, a pesar de esa gigantesca movilización de recursos materiales y humanos, a principios de enero de 1331, se observan síntomas de un nuevo aplazamiento - esta vez, sería definitivo- de la gran expedición cruzada; en consecuencia, fue sobreseído el servicio feudal y se suspendió el cobro de las redenciones de las milicias urbanas ${ }^{23}$.

Pero, antes de que se formulase de manera clara y explícita el aplazamiento de la expedición, las Órdenes fueron citadas para prestar el servicio a mediados de abril de 1331 en Orihuela ${ }^{24}$. Con la misma fecha, el Benigno se dirigía a Helio de Villanueva para anunciarle esta convocatoria y rogarle que no pusiese obstáculos a la marcha de los hospitalarios a la frontera; desde Marsella, el maestre respondió que su intención no era impedir a los freires el cumplimiento del servicio que debían por la castellanía y el priorato y que, para mayor seguridad, ya les había escrito en este mismo sentido ${ }^{25}$. Con el fin de facilitar su marcha, y dado que los freires se exponían en la frontera pro re et utilitate publica, el monarca ordenó a sus oficiales la suspensión, mientras durase dicho servicio, de las ejecuciones judiciales por las deudas contraídas por los súbditos de la castellanía $^{26}$. Pero la cruzada estaba en punto muerto y, en consecuencia, la citada convocatoria fue sobreseída. Con todo, ciertos rumores de entrada de los nazaríes por la frontera motivaron a principios de mayo una llamada de alerta a los hospitalarios: como en otras ocasiones, se les ordenaba estar preparados para un nuevo aviso y, al mismo tiempo, se les recordaba que las

\footnotetext{
${ }^{23}$ Sobre este definitivo aplazamiento de la cruzada, uno de los aspectos más controvertidos de la misma, véanse M. SÁNCHEZ, La Corona de Aragón y Granada en el s. XIV, tesis doctoral, II, pp. 744-757 y un resumen en M. SÁNCHEZ, Guerra, p. 537, nota 56.

${ }^{24}$ Por lo que respecta al Hospital, además del castellán y del prior, se convocaron también a los comendadores de las casas del Rosellón; C, reg. 541, fols. 165r.-v. Es posible que ello tenga que ver con el conflicto entre el rey y el maestre, desencadenado a raiz de la segregación, ordenada por éste con la oposición del Benigno, de las encomiendas de Masdeu y Bajoles del priorato de Cataluña; reg. 523, fols. 42r.-v. y reg. 525, fol. 120r., cit. por LUTTRELL, The Aragonese Crown, p. 10.

${ }^{25} \mathrm{C}$, reg. 541, fol. $165 \mathrm{v}$. y Cr. Alfons III, n.0 3235.

${ }^{26} \mathrm{C}$, reg. 541 , fol. $170 \mathrm{v}$.
} 
responsiones no debían ser pagadas al maestre sino que se invertirían en el propio servicio ${ }^{27}$.

La atonía de la primera mitad de 1331 , por lo que se refiere a la actividad en la frontera, fue bruscamente sacudida por el brutal asalto nazarí a Guardamar ${ }^{28}$. El Benigno procedió inmediatamente a la movilización masiva de todos los recursos bélicos de la Corona, ya que existía la sospecha del retorno de los nazaríes; en este sentido, las Órdenes fueron alertadas para estar preparadas y acompañar al rey en su prevista y rápida marcha hacia la frontera ${ }^{29}$. A principios de noviembre, corrieron nuevos rumores sobre la presencia en la zona del propio Muhammad IV, por lo que todos los freires del Hospital fueron convocados para acudir a la frontera con la mayor comitiva posible; $\mathrm{y}$, de nuevo, se ordenaba retener las responsiones con el fin de ser empleadas en gastos de la expedición ${ }^{30}$. Pero, esta vez, los intentos del monarca para usar de las responsiones chocarían con los problemas derivados del cisma producido en el seno del priorato de Cataluña (¿fue ésta la razón de la convocatoria individualizada de algunos comendadores?); ello estuvo en la base de la adopción de un conjunto de medidas tendentes, en última instancia, a impedir que saliese del reino el tributo

\footnotetext{
${ }^{27} \mathrm{C}$, reg. 541 , fol. $177 \mathrm{r}$.

${ }^{28}$ Sin duda alguna, nos encontramos ante el suceso militar más espectacular ocurrido en la frontera oriental entre 1329 y 1334. El ejército nazarí, dirigido por el visir Ridwan, se concentró en Vera, desencadenó una ofensiva general en la zona y atacó Guardamar (18 y 19 de octubre de 1331) así como otras alquerías de la región de Orihuela y Elche; según algún testimonio, los nazaríes capturaron 1.500 personas y se llevaron consigo un elevado número de cabezas de ganado así como considerables cantidades de grano. Sobre este asalto y otros sucesos fronterizos del otoño de 1331, véanse M. SÁNCHEZ, La Corona de Aragón, II, pp. 771-784 y $M^{\mathrm{a}}$ T. FERRER MALLOL, La frontera amb l'Islam, pp. 127-131.

${ }^{29} \mathrm{C}$, reg. 539, fol. $64 \mathrm{v}$.; véase el pregón leído al respecto en la encomienda de Monzón en MIRET I SANS, Les cases, p. 405.

${ }^{30} \mathrm{C}$, reg. 539 , fols. 69 r. $-\mathrm{v}$. y reg. 534 , fols. $25 \mathrm{v} .-26$ r. Parece interesante transcribir las razones que justificaban la licitud regia a disponer de los bienes de la Orden: ello es así porque los comendadores "infra nostrum dominium constituti ad serviendum Deum et nobis in ffrontaria...sitis astricti et bona ipsius ordinis...sint ad idem, maxime in presenti casu et similibus, specialiter obligata.."; reg. 539, fol. 69r. En este caso concreto, además del castellán, el prior y el comendador de Monzón, fueron convocados individualmente los siguientes comendadores del priorato de Cataluña: Domingo de Mallén (Avinyonet), Albert Savellà (Sant Celoni), Guillem de Millars (Barcelona), Lope Mendez (Les Gunyoles), Berenguer de Flassà (de la casa antigua de Lleida, Vilafranca y Tèrmens), Berenguer de Llorach (Cervera y Gardeny), Mateu Llonc (Siscar y Susterris) y Arnaldó d'Alós (Torres).
} 
debido por el prior ${ }^{31}$. En efecto, la existencia de dos priores, uno reconocido por el papa y el maestre (A. d'Olms) y otro por el monarca (A. d'Alós) daría una nueva y más grave dimensión a las tensiones entre la monarquía y el Hospital. Así, cuando Alós fue enviado a la frontera a principios de diciembre de 1331 , el rey conminó a los comendadores del priorato a pagar las responsiones solamente a aquel y no a ningún otro (naturalmente, a Olms) $)^{32}$. Y todavía fue más lejos: en la misma fecha, y puesto que el servicio de Sancho de Aragón y de Arnau d'Alós en la frontera no sería posible si las responsiones se pagaban al maestre, los oficiales ordinarios recibieron la orden de pregonar en sus respectivas jurisdicciones que los mercaderes y cambistas no hiciesen dites en nombre del castellán y del prior. Un mes después, el monarca volvía a insistir en lo mismo de forma todavía más enérgica: para evitar que las responsiones saliesen de la Corona subrepticiamente, el Benigno ordenaba a Sancho y a Alós que las depositasen en el convento de los franciscanos de Lleida para ser gastadas por el propio monarca en lo que considerase necesario ${ }^{33}$. La posición del prior, reconocido sólo por el rey frente al papa y el maestre, no debía ser muy cómoda: para justificar mejor su permanencia en el priorato quizás sólo le cabía el cumplimiento puntual del servicio de frontera; sea como fuese, a mediados de noviembre, Alós marchaba a la región oriolana, donde está efectivamente atestiguado a finales de 1331 y parte de $1332^{34}$.

En ese clima de rumores de invasión nazarí y de sucesivos desmentidos que caracterizó la vida fronteriza durante los últimos dias de

\footnotetext{
${ }^{31}$ En dos palabras, recordemos que, en 1330, Arnau d'Alós fue desposeido del priorato y excomulgado por desobediencia y mala administración de las propiedades de la Orden; en su lugar, fue nombrado Arnau d'Olms. El rey no reconoció este nombramiento - vale la pena recordar que Alós había sido elevado al priorato por influencia del entonces infante Alfonso y siguió considerando a aquel como único prior de Cataluña; véanse, entre otros, J. DELAVILLE LE Roulx, Les Hospitaliers ì Rhodes (1310-1421), Paris, 1913 [reimp., London, 1974], pp. 66-67 y LuTtRell, The Aragonese Crown, p. 12

${ }^{32} \mathrm{C}$, reg. 541 , fols. $183 \mathrm{r} .-\mathrm{v}$.

${ }^{33}$ C, reg. 541, f. 183r. (cit. por LutTRELl, The Aragonese Crown, p. 9, nota 3) y 185r.-v.

${ }^{34}$ Los oficiales de la Corona recibieron la orden de aplazar toda causa judicial incoada contra Alós y el priorato hasta su regreso de la frontera (C, reg. 541, fols. 183r.-v.). Asímismo, con la finalidad de sufragar mejor el servicio, el rey mandó al veguer de Cervera que autorizase a Alós a arrendar durante un año las rentas de la encomienda cerverana; véanse otros ejemplos de esta práctica, para una época posterior, en M. BONET, op. cit., pp. 213-223. Un año más tarde, cuando el Benigno tenga que defender ante Juan XXII la reposición de Alós al frente del priorato aducirá precisamente sus puntuales servicios en la frontera; así se observa, por ejemplo, en la embajada de B. Oliver y G. Richer ante el pontífice; C, reg. 544, fols. 3r.-v.
} 
1331 y los primeros meses de 1332, en diciembre de aquel año tuvo lugar otra convocatoria de todas las Órdenes ${ }^{35}$. Pero esta nueva llamada del monarca fue oportunamente soslayada por el castellán y el prior: reunidos con el Benigno en Valencia (en presencia también del maestre de Montesa), $y$ tras exponer que no era previsible una entrada de los musulmanes en plena estación invernal, consiguieron aplazar su servicio hasta la primavera de $1332^{36}$.

A principios de ese año se confirmó la existencia de una firme alianza entre Granada y Génova, lo cual dió un nuevo signo a la guerra, planteada ahora como la defensa de la fachada marítima catalanoaragonesa de los posibles ataques conjuntos de ligures y nazaríes. Por lo que respecta a la frontera, una vez desmentidos los rumores de la muerte de Muhammad IV, a finales de enero llegaron noticias del próximo viaje del sultán a Almería, donde ya le aguardaba el visir Ridwan. Puesto que, dado el cariz de tales rumores, se esperaba una invasión en firme, Jaume de Xèrica pedía al rey que enviase a las Órdenes lo más pronto posible; en consecuencia, el 28 de enero, el Benigno adelantaba la convocatoria de los freires, quienes debían acudir de inmediato a Orihuela ${ }^{37}$. Pero enseguida volvieron a manifestarse reticencias por parte de los hospitalarios: en una carta sin fecha, pero desde luego anterior a mediados de febrero, Sancho de Aragón pedía al rey el aplazamiento de su servicio; entre otras razones, aludía a los grandes gastos hechos en los largos y frecuentes viajes a la cort de Roma y en pagar las responsiones al maestre; además, dada la premura de la convocatoria, no había tenido tiempo de reunir el dinero de los comendadores, "ans se me escusen per rahó de la mala anyada que és estada e ara que no poden traure diners de neguna casa per a les messions en la dita frontera"; por tanto, le pedía tiempo para celebrar capítulo ${ }^{38}$. Pero el rey no escuchó estas razones $\mathrm{y}$, dado que el servicio era urgentemente necesario, amenazó a Sancho de Aragón con incautar los bienes de la castellanía y

\footnotetext{
${ }^{35} \mathrm{C}$, reg. 541 , fol. $184 \mathrm{v}$. Se precisaba de nuevo el número de caballos que debía llevar el castellán (30), el prior (20), el maestre de Montesa (30), el de Calatrava (15) y el comendador de Montalbán (10).

${ }^{36} \mathrm{C}$, reg. 541 , fols. $187 \mathrm{r}$.-v.

${ }^{37} \mathrm{C}$, reg. 541 , fol. $188 \mathrm{v}$. y reg. 534 , fol. $49 \mathrm{v}$. Sobre todo este período, véase M. SÁNCHEZ, La Corona de Aragón, tesis doctoral, II, pp. 785-796.

${ }^{38} \mathrm{C}$, Cr. Alfons III, $\mathrm{n}^{0} 3240$.
} 
formar con su producto un contingente armado para ser enviado a la frontera $^{39}$. Muy pronto, pasaría a los hechos: una vez comprobada la incomparecencia de los hospitalarios en Orihuela a primeros de marzo, el rey decidió enviar en su defecto a Jaume de Xèrica con una compañía de 100 caballos a cargo de la castellanía y del priorato ${ }^{40}$. Pocos dias después, el monarca daba potestad al tesorero Felip de Boil para vender y obligar los castillos, villas y lugares (o sus rentas respectivas) de las Órdenes del Hospital, de Calatrava, de Montesa y de la encomienda de Montalbán y emplear su producto en estipendios de los combatientes de a caballo y de a pie que iban a ser enviados a la frontera ${ }^{41}$. La firme decisión regia de poner en práctica la amenaza debió surtir efecto pues, diez dias después, el castellán prometía reunir un capítulo en Gandesa, donde se congregarían los comendadores y freires para marchar a la región fronteriza ${ }^{42}$. Ese capítulo quizás tuviese los resultados apetecidos por el rey pues, antes de dos semanas, a finales de marzo, los oficiales recibieron la orden de que no se

\footnotetext{
${ }^{39} \mathrm{C}$, reg. 541 , fol. $189 \mathrm{v}$. Parece interesante subrayar el interés del rey en que la frontera fuese defendida, sobre todo, por las Órdenes: por ejemplo, a finales de febrero de 1332 , prohibía a Jofre Gilabert "fer cavalcades e entrades entrò que y sien los cavallers de les Òrdens, los quals hi deven anar de present"; C, reg. 534, fols. 63r.-v.

${ }^{40}$ El portero Pere de Cardonets quedó encargado de percibir, de los bienes de la castellanía, $6 \mathrm{sb}$. por cada uno de los 60 caballos armados con que Sancho de Aragón debía servir y la misma cantidad en el priorato por 40 caballos; C, reg. 541, fols. 190v.-191v. y 193r.-v. Con la misma fecha, Jaume de Xèrica recibía la orden de dirigirse a Orihuela con los 100 caballos pagados con el valor de los bienes ocupados: reg. 541, fols. 192r.-v. Por cierto, la presencia de Xèrica planteó ciertos problemas de carácter jurisdiccional con miembros de la orden: a mediados de mayo de 1332, cuando este noble exigía a Guillem de Guimerà -enviado a la frontera como lugarteniente de Sancho de Aragón- ponerse a sus órdenes, el comendador había respondido (según la referencia de la correspondiente carta real) que la bandera de la vostra orde ne vosaltres negun temps no havets acostumat de anar en obediència de negun seglar sinó solament del rey d'Aragó; Alfonso el Benigno recordaba a Guimerà que en la dita frontera (Jaume de Xèrica) tinga nostre loch y, en consecuencia, el comendador estaba obligado a obedecerlo como si fuese la propia persona del rey; reg. 541 , fols. $204 \mathrm{v} .-205 \mathrm{r}$. Creo que este documento muestra perfectamente la posición de los hospitalarios como vasallos del monarca y su dependencia en este sentido de la Corona. En cualquier caso, parece evidente que esos conflictos de orden jurisdiccional tampoco debían coadyuvar al éxito de la guerra fronteriza.

${ }^{4 \prime} \mathrm{C}$, reg. 526, fols. $172 \mathrm{v} .-173 \mathrm{r}$.

${ }^{42}$ El rey ordenó al portero Cardonets que aguardase tres semanas - la duración prevista del capítulo gandesano- antes de proceder a la incautación y subasta de los bienes; C, reg. 533 fol. 143v. Es sabido que en los capítulos provinciales se recaudaban los tributos debidos a Rodas; es posible que, en el de Gandesa, el castellán esperase obtener el dinero necesario para emprender la expedición.
} 
percibiese hostalatge, por personas y animales, de los comendadores y freires de la castellanía que se dirigían a la frontera ${ }^{43}$.

Como acabo de apuntar, la alianza Génova-Granada hacía temer un ataque combinado en las zonas costeras de Alicante o Denia; por esta razón, tanto las Órdenes como los otros combatientes movilizados debían acudir con preferencia a defender las costas alicantinas ${ }^{44}$. De repente, el 9 de abril, el visir Ridwan se presentó ante Elche con un importante contingente armado; el rey se puso en marcha precipitadamente desde Tortosa, no sin antes convocar de nuevo, por separado, a diversos comendadores del priorato, los mismos que lo fueron en noviembre de $1331^{45}$. Pero, hicieron caso omiso: casi un mes después, los citados comendadores aún no se habían movido de sus encomiendas y el rey volvía a amenazarlos con hacer cumplir el servicio con el producto de los bienes y rentas de las mismas ${ }^{46}$. Mientras tanto, Arnau d'Alós continuaba en la frontera y, en compañía del maestre de Montesa y de Jaume de Xèrica, protagonizaba una incursión por la región de Vera ${ }^{47}$.

\footnotetext{
${ }^{43}$ C. reg. 541, fol. $196 \mathrm{v}$.

${ }^{H}$ En este sentido, a finales de abril. se ordenaba a Guillem de Guimerà abandonar inmediatamente Orihuela y marchar hacia Alicante; los oriolanos debian permitir a los hospitalarios extraer vituallas para transportarlas a aquella villa; $C$, reg. 533 , fols. 160r.-v. y reg. 541 . fols. $200 \mathrm{v} .-201 \mathrm{r}$. y $203 \mathrm{r}$. Véanse algunas referencias a Guillem de Guimerà en LutrRell, The Aragonese Crown, pp. 13 y ss.; Hospitaller life in Aragon, p. 111; The Structure of the Aragonese Hospital, pp. 321 y $326 ;$ y J.M ${ }^{a}$ SANS I TRAVÉ, Guillem de Guimerà, "Arrels. Miscel lània d'Aportacions Històriques i Documentals de l'Espluga de Francolí". III (L’Espluga de Francolí, 1989), pp. 34-36.

${ }^{45} \mathrm{C}$, reg. 539, fol. 83r. En esta relación no aparece el castellán, ya que su lugarteniente Guimerà hacía el servicio en Alicante, ni Alós, presente en la frontera desde finales de 1331. De nuevo se recordaba al castellán y al prior retener las responsiones hasta que el monarca dispusiese su destino; reg. 541, fol. 199r. Sobre el asalto a Elche, véanse M. SÁNCHEZ, La Corona de Aragón, tesis doctoral. II, pp. 810-814 y $\mathrm{M}^{\mathrm{a}}$ T. FERRER MALLOL, La frontera (amb) l'Islam, pp. 131-134.

${ }^{46} \mathrm{C}$. reg. 541, fol. 200r. Pocos dias más tarde, el Benigno conminaba a los comendadores de Barcelona y de Les Gunyoles a emprender la marcha; en caso contrario, los veguers correspondientes procederían a incautar las rentas de las encomiendas y pagar con ellas una comitiva adecuada; reg. 541. fols. 203v.-204r. y 209v.

${ }^{47} \mathrm{~A}$ mediados de agosto de 1332, el rey le ordenaba pagar a los musulmanes del valle de Elda la indemnización debida por las acémilas tomadas de ellos y perdidas en la incursión; $C$, reg. 499, fol. 108v. Esta entrada en tierras nazaries fue desautorizada por el Benigno, al tiempo que prohibía futuras penetraciones mientras no hubiese total garantía de éxito; reg. 533, fol. 180r. Todavía bien avanzado el mes de septiembre, Alós seguía en Alicante, donde debía permanecer hasta mediados de octubre para defenderlo de un presunto ataque granadinogenovés; reg. 541, fols. 210r.-v.
} 
A finales de junio de 1332 se dió un paso más en la escalada de conflictos entre la orden hospitalaria y la Corona. Quizás porque estimaban que no estaban obligados a servir pasado determinado número de dias, los comendadores de la castellanía abandonaron masivamente la frontera, sin autorización real, y se dirigieron a sus respectivas encomiendas. Considerando, entre otras cosas, que ello iba en detrimento del servicio que estaban obligados a cumplir y, finalmente, en daño de la res publica, el monarca ordenó a los sobrejunteros aragoneses y al batlle de Valencia que ocupasen las encomiendas y las entregasen a bonis personis et fidedignis dicti Ordini minus sumptuosis, para que las administrasen y convirtiesen sus rentas en la guerra fronteriza ${ }^{48}$. Sancho de Aragón (en presencia del prior de Cataluña y del maestre de Montesa) hizo algunas alegaciones ante el rey sobre la duración del servicio fronterizo, lo que motivó sendas reuniones del Consejo real - con prelados, barones y peritos-, que deliberó sobre la cuestión y acordó finalmente que el castellán estaba obligado a cumplir todo el servicio que se le exigía y que, en ningún caso, podía justificarse el abandono de la frontera por parte de los comendadores ${ }^{49}$.

A lo largo de los dos años siguientes, quedó patente que la gran expedición que el Benigno había imaginado no se llevaría a cabo: como he apuntado, la cruzada había quedado convertida en una guerra defensiva de carácter predominantemente marítimo, por lo que la actividad registrada en la frontera oriental fue muy escasa. Sin embargo, seguimos encontrando convocatorias a los freires, ausencias significativas de la frontera y amenazas regias, en los mismos términos que ya hemos visto. Bastará, por tanto, con aludir muy brevemente a estas cuestiones.

${ }^{48} \mathrm{C}$, reg. 541 , fols. $206 \mathrm{v} .-207 \mathrm{v}$. Se iba a escribir una carta idéntica referida a las encomiendas del priorato, pero Alós - presente en el séquito del rey - se apresuró a certificar que tenía una comitiva de combatientes a caballo en la frontera. En todo caso, es posible que el monarca dudase antes de proceder a esta dura medida o. en todo caso. de la forma de llevarla a cabos; ello parece desprenderse de una carta dirigida a comienzos de julio a Bonanat Sapera. tenente de los sellos, donde se le ordenaba buscar en los registros de Jaime II y en otra documentación del Archivo Real precedentes de la ocupación de los bienes de las Órdenes y del secuestro de las responsiones debidas al maestre para ser empleadas en la defensa del territorio; asímismo, Sapera debía buscar traslados de las donaciones hechas por los reyes a las Órdenes y enviar a Valencia todo el material localizado; C. reg. 526. fols. 235r.-v. Recordemos que, ya en 1320. Jaime II había ordenado el secuestro de 76.000 s.. procedentes de bienes de la Orden, para suplir el servicio de los 80 combatientes a caballo exigidos para servir en la frontera nazarí; cf. LuTTRELL, The Aragonese Crown, pp. 8-9.

${ }^{+10} \mathrm{C}, \mathrm{Cr}$. Alfons III, n" 1943 y reg. 539, fol. 95v.; reg. 556. fol. 6r. y reg. 541, fols 207v.-208r.: cit. por LUTTRELL. The Aragonese Crown, p. 9, nota 3. 
El año 1333 comenzó con una convocatoria tópica a los comendadores de la castellanía y del priorato, así como al resto de las Órdenes, para estar en la frontera a mediados de abril; pero, una vez más, los freires de la castellanía no acudieron en la fecha fijada ${ }^{50}$. Durante la segunda mitad del año, sabemos del servicio prestado por ciertas encomiendas, aunque con unos contingentes ridículamente escasos: por ejemplo, el comendador de Monzón se limitó a enviar una comitiva de tres caballos, que el monarca consideraba insuficiente teniendo en cuenta la entidad de dicha encomienda y la misión conferida a los freires ("dictam comendariam que inter alias notabilis esse dinoscitur et insignis et cuius bona fuerunt a nostris progenitoribus donata et concessa specialiter pro defensione occidentalis Ecclesie contra perfidos Hispanie sarracenos" $)^{51}$. Más tarde, el rey supo que Sancho de Aragón no sólo había enviado a la frontera una escasa compañía sino que los freires habían abandonado la zona sin autorización regia; ante las muestras reiteradas de tanta desobediencia - dice el documento-, el Benigno le ordenó entregar al tesorero $30.000 \mathrm{sb}$. de la castellanía para formar un contingente apropiado ${ }^{52}$.

Por fin, a principios de 1334, todas las Órdenes de la Corona fueron nuevamente convocadas, volviéndose a especificar, como en otras ocasiones, el número de caballos a llevar por cada maestre y comendador; y otra vez

\footnotetext{
${ }^{50} \mathrm{C}$, reg. 539, fol. 99r. y Cr. Alfons III, n” 1827. Sancho de Aragón se excusó diciendo que debía celebrar capítulo, mientras el rey le reprochaba una demora intencionada en la fecha de su reunión, pues ésta podía haber tenido lugar en una época más oportuna con el fin de no obstaculizar el servicio; con todo, le concedió un plazo de quince dias para incorporarse a la frontera. Pero, ni Sancho ni los otros comendadores y maestres acudieron, por lo que el monarca se limitó a volverles a exigir el servicio desganadamente y bajo las amenazas habituales: C, reg. 539, fol. 99v. En esta última convocatoria, el rey se dirigía ya al prior Arnau d'Olms en lugar de a Arnau d'Alós; según LutTrell, The Aragonese Crown, p. 12, presionado por el papa, el rey reconoció a Olms en abril de 1333, aceptándolo como prior de Cataluña, sin perjuicio de que Alós continuase su servicio fronterizo. En efecto, el primero de julio, el Benigno pedía a Olms que entregase a Alós los $10.000 \mathrm{~s}$. que necesitaba para cumplir dicho servicio; cf. J. VINCKE, Documenta selecta mutuas civitatis Arago-Cathalamicate et Ecclesiae relationes illustrantia, Barcelona, 1936, doc. 503; cit. por LUTTRELL, art.cit., p. 12.

${ }^{5} \mathrm{Si}$ no acudía personalmente con un número mayor de caballos, el sobrejuntero de Sobrarbe tomaría $20.000 \mathrm{sb}$. de la encomienda y los emplearía en el estipendio de otros combatientes; C. reg. 539, fol. 104r. El comendador Saluces debió marchar a Montblanc, donde estaba el rey, quizás para justificar su ausencia o protestar por la medida; el caso es que el Benigno ordeno al sobrejuntero citado el sobreseimiento de las medidas contra la encomienda; reg. 539, fols. 104r.-v.

${ }^{52} \mathrm{C}$, reg. 539 , fol. $104 \mathrm{v}$. Al parecer, a principios de verano, el rey debió pedir al castellán 1.000 cahices de trigo - no olvidemos que estamos en 1333, lo mal any primer-, pero Sancho confesó no disponer de ellos debido a los gastos de la frontera y a las deudas que oprimían a la castellanía; C, Cr. Alfons III, n" 2326.
} 
volvemos a encontrar síntomas de resistencias, en este caso, por parte del prior de Cataluña, Arnau d'Olms ${ }^{53}$. A pesar de estas precauciones defensivas, el asesinato de Muhammad IV en agosto de 1333 y el acceso de Yusuf I al sultanato granadino abrieron el camino hacia el futuro tratado de paz entre la Corona de Aragón y el reino nazarí, que, no obstante, aún tardaría casi dos años en firmarse ${ }^{54}$.

\section{LAS OTRAS ÓRDENES}

\section{A) La Orden de Montesa}

A diferencia de la Orden hospitalaria, la bibliografía es bastante escasa por lo que respecta a Montesa y, en consecuencia, es mucho más difícil insertar las noticias aisladas que he logrado localizar en el contexto general de su historia ${ }^{55}$. No obstante, los datos que he reunido permiten afirmar, con todas las reservas y provisionalidad que se quiera, que, frente a lo observado en el caso del Hospital, la Orden de Montesa cumplió con puntualidad su servicio de frontera y que, en términos generales, se mostró realtivamente dócil a los propósitos de la monarquía. No es difícil entenderlo, aunque ésto no pase de una mera formulación general, que no explica del todo la actitud concreta de la Orden entre 1329 y 1331 : fundada reciente y directamente por Jaime II (1319) como heredera del patrimonio templario y (en parte) hospitalario, y favorecida por importantes privilegios, Montesa era

\footnotetext{
${ }^{53} \mathrm{C}, \mathrm{Cr}$. Alfons III, n" 2147 y reg. 539, fols. 109r.-v. Ante la insistencia del prior Olms, que aducía enfermedad, el monarca le dispensó el servicio, pero le obligó a pagar, a cambio, la suma de $25.000 \mathrm{sb}$. en dos plazos (abril y agosto de 1334), según composición hecha entre Olms y el jurista P. Bosom (C. reg. 535, fols. 56v.-57r.); sin embargo, transcurrido abril, todavia no había hecho efectivos los 12.000 sb. del primer plazo (reg. 535, fol. 69r. y reg. 536, fol. $2 \mathrm{r}$.); y, a principios de agosto, se le recordaba el pago del segundo plazo; reg. 529, fols. 75v.-76r., cit. por LUTTRELL, art.cit., p. 9.

${ }^{54}$ Véase un sucinto resumen del largo e incierto período que transcurre entre agosto de 1333 y junio de 1335, fecha de la adhesión catalanoaragonesa a la paz entre Castilla, Granada y los marinies en M. SÁNCHEZ, El control del corso valenciano (1334) en el marco de la paz entre la Corona de Aragón y los sultanatos de Granada y Fez, "Homenaje al Prof. Jacinto Bosch Vilà $(\dagger)$ ". Universidad de Granada, 1991, I, pp. 349-353.

${ }^{55} \mathrm{Como}$ dice E. Guinot, todavía no disponemos de una historia, ni siquiera superficial, de la Orden de Montesa y los trabajos recientes más accesibles no pasan de la mera divulgación general; véase un balance sobre las fuentes y bibliografía en E. GUINOT, Els estudis sobre i'Orde de Montesa en tempss medievals i les seues bases documentals, "Saitabi", XLIV (1994), pp. 23-32.
} 
una Orden específicamente catalanoaragonesa y no dependía de ninguna obediencia internacional.

Las convocatorias hechas por Alfonso el Benigno a Montesa para realizar el servicio fronterizo se produjeron en las mismas fechas - generalmente, se contienen en la misma carta/circular- que las dirigidas a los Hospitalarios. Por tanto, bastará con observar exclusivamente algunas incidencias de su participación en la cruzada. Así, durante 1329, el maestre Pere de Tous fue convocado en cuatro ocasiones ${ }^{56}$. Según se deduce de una referencia indirecta, la Orden debió ser llamada para efectuar el servicio otra vez en la primavera de 1330: en el mes de mayo, y con el pretexto de los gastos que generaría su marcha a la frontera, el monarca absolvía a la Orden de los cargos imputados a causa de la exportación de grano por Peñíscola y Alcocéber ${ }^{57}$. Y, a finales de agosto, Pere de Tous, junto con el prior de Cataluña, Jofre Gilabert y otros intervenía en la algara fronteriza que hemos comentado brevemente más arriba.

A comienzos de 1331, y como el resto de comendadores y maestres, Tous recibió la orden de presentarse en Orihuela a mediados de abril ${ }^{58}$. Es posible que, durante gran parte del otoño de 1331, algunos freires de la Orden estuviesen presentes en la frontera pues en las convocatorias de octubre y noviembre, motivadas por el asalto a Guardamar, no aparece Pere de Tous. Recordemos que, a finales de diciembre y a requerimiento de Sancho de Aragón, de Arnau d'Alós y de Pere de Tous, presentes en Valencia, el rey aplazó sus correspondientes servicios hasta el primero de

${ }^{56}$ El 15 de marzo, el 29 de abril, el 20 de julio y el 15 de septiembre: C. Cr. Alfons III, n" 2147 y reg. 539 , fols. $38 \mathrm{v}$. $-40 \mathrm{r}$. Como hemos visto, en la convocatoria del 20 de julio parece - el folio del registro está dañado en este preciso punto - que se le exigía un servicio de 60 caballos.

${ }^{57}$ En efecto, a pesar de las prohibiciones generales emanadas de Jaime II y de Alfonso el Benigno, el maestre de Montesa concedía licencias particulares para sacar cereal por los lugares citados: ello iba en detrimento, no sólo de las regalías sino de los compromisos adquiridos por el rey en las recientemente celebradas cortes de Valencia: ef. M. Sánchez. Guerra, pp. 543545. A pesar de todo, el rey absolvía al maestre. a los comendadores, batlles y escribanos de Peñíscola y Alcocéber de todos los cargos. tras una composición de $25.000 \mathrm{~s}$. acordada con el tesorero real: C, reg. $481, \mathrm{ff} .188 \mathrm{v} .-189 \mathrm{r}$.

${ }^{58} \mathrm{El}$ servicio fue posteriormente prorrogado y de nuevo requerido a finales de mayo: C. reg. 541, fols. 165r.-v. y 178r. Es de notar que, en casi todas las convocatorias dirigidas a la Orden de Montesa. se excluía la cláusula comminatoria que. de forma habitual, se contenía en las enviadas a los Hospitalarios; este simple detalle quizás sirva para mostrar la diferente actitud del monarca hacia una y otra Orden. 
marzo de $1332^{59}$. Por estas fechas, según la propia confesión del maestre, la Orden atravesaba serias dificultades económicas, motivadas, entre otras causas, por los préstamos contraídos para pagar la pensión que Montesa debía abonar anualmente al Patriarca de Alejandría; a pesar de todo, Tous estaba dispuesto a marchar a la frontera y pedía instrucciones al rey sobre el lugar más adecuado para servir, si Orihuela o Alicante ${ }^{(1)}$. Como ya hemos visto, a principios de marzo de 1332, se produjeron los intentos de ocupación de algunos bienes del Hospital para ser empleados en la cruzada; de esta medida se libró Montesa gracias al aparentemente puntual cumplimiento de sus obligaciones militares; satisfecho, el rey se lo comunicaba al maestre - "fecistis quod sperabamus de vobis et semper facturum credebamus" - y le respondía que efectuase el servicio allí donde lo considerase más eficaz ${ }^{61}$. Durante la primavera de este año, los freires de Montesa debieron continuar en la frontera pues, a principios de mayo, el rey escribía a Bernat de Montsonís y a G. de Guimerà, lugartenientes del maestre de Montesa y del castellán de Amposta, para anunciarles la llegada de Jaume de Xèrica y solicitarles su colaboración con éste ${ }^{62}$. El servicio de la Orden, con Tous a su frente, continuó durante el verano y, en la primera quincena de agosto, el maestre protagonizó una algara en territorio granadino en compañía del prior de Cataluña (véase supra nota 47). Por fin, está atestiguada la presencia del maestre de Montesa en Alicante a finales de noviembre, cuando el rey le prevenía - a él y a Arnau d'Alós- de las 55 galeras

${ }^{59} \mathrm{C}$, reg. 541 , fols. $187 \mathrm{r}$.-v.

${ }^{60}$ El maestre mostraba su buen talante para servir, pero "per gran pobrea e necessitat. senyor, que és en l'Orde, que major no poria a adés per rahó de la pensió quél senyor patriarcha, vostre frare, pren de nostra Orde, s`és trigat tro ara e no per nenguna altra rahó. car, sap-ho Déus, senyor, a qui mentir no podem, que molt més amariem, si aparellat-ho haviem, ésser a honor e serviy de Déu e vostre en la dita frontera que no ésser ací" (C. Cr. Alfons III, $n^{\circ}$ 1494). En efecto, sabemos que el fondo común de la orden debía pagar cada año 2.000 I. al patriarca; of. L. García-guiJarRo Ramos, Datos para el estudio de la renta feudal maestral de la orden de Montesa en el s.XV. Valencia, 1978. p. 40. El rey acudiría en socorro de la Orden a finales de 1332: los embajadores B. Oliver y G. Richer solicitaron a Juan XXII, entre otras cuestiones, que liberase a Montesa del pago de la pensión al patriarca, pues no sólo dificultaba el servicio fronterizo sino que había obligado a la Orden a vender y empeñar castillos y villas. El Benigno proponía al papa compensar al patriarca con la abadia de Ager, el priorato de la sede tortosina y los beneficios vacantes por la muerte de Hug de Cardona; C, reg. 544. fols. $5 r .-6 v$.

${ }^{61}$ La reina Leonor escribiría a sus oficiales de Alicante y Orihuela para que los freires fuesen bien acogidos y no se les cobrase hostalatge; $\mathrm{C}$, reg. 541 , fols. 194r.-v.

${ }^{62} \mathrm{C}$, reg. 541 , fol. $203 \mathrm{r}$. 
genovesas que habían sido avistadas en Cadaqués con dirección al sur del reino valenciano ${ }^{63}$.

Pero, si el servicio de Montesa está documentado durante la mayor parte de 1332, no ocurrió lo mismo al año siguiente. Sabemos que la convocatoria hecha el 12 de febrero de 1333 a todas las Órdenes no fue atendida por los freires y, a mediados de junio, el rey insistía todavía en la absoluta necesidad de defender la frontera ${ }^{64}$. A pesar de todo, el rey continuaba confiando en la colaboración de la Orden: así, cuando el procurador Jofre Gilabert de Cruilles tuvo que abandonar temporalmente la frontera, el rey encomendó a su hermano, Dalmau de Cruïlles, freire de Montesa, la custodia de la región hasta el regreso del procurador ${ }^{65}$. En 1334, y cuando ya se negociada la paz con Granada, Pere de Tous quedó incluído en las ya citadas convocatorias de principios de ese año, sin que tengamos la certeza del cumplimiento del servicio ${ }^{66}$.

\section{B) La Orden de Calatrava (encomienda de Alcañiz)}

Como es sabido, diversas circunstancias convirtieron a la encomienda calatraveña de Alcañiz casi en una Orden catalanoaragonesa durante el primer tercio del s.XIV. Recordemos que, en 1325, el maestre de Calatrava Garci López de Padilla fue depuesto a instigaciones del clavero Juan Núñez de Prado; sin embargo, el rey de Aragón siguió reconociendo como único maestre a Garci López, residente en la encomienda de Alcañiz, provocando

\footnotetext{
${ }^{63}$ Debían poner atalayas en Alicante y avisar a Xèrica cuando se tuviese la certidumbre de la proximidad de los navíos; C, reg. 537, fol. 98v.

${ }^{64} \mathrm{C}, \mathrm{Cr}$. Alfons III, $\mathrm{n}^{0} 1827$ y reg. 539, fols. 99r.-v. Aunque, en principio, no guarde relación con la cuestión que aquí nos interesa, vale la pena recordar que, por esta época, los habitantes de las villas y lugares de Montesa se negaban a contribuir en la nueva imposició establecida en el reino de Valencia; en abril de 1333, el rey pedía a Tous su colaboración para lograr que aceptasen el impuesto; C, reg. 534, fol. 118v.; sobre esta "nueva" imposició de mediados de 1333, véase M. SÁNCHEZ, La contribución valenciana a la cruzada granadina de Alfonso IV de Aragón, "Primer Congreso de Historia del País Valenciano", II, Valencia, 1981, pp. 579-598

${ }^{6.5} \mathrm{C}$, reg. 535, fols. $16 \mathrm{r} .-\mathrm{v}$.

${ }^{66} \mathrm{C}, \mathrm{Cr}$. Alfons III, n" 2147 y reg. 539, fols. 109r.-110v.
} 
así el llamado "tercer cisma" de la orden y la existencia insólita de una orden de Calatrava "aragonesa", enfrentada a la castellana ${ }^{67}$.

No he logrado documentar con precisión el grado de cumplimiento del servicio fronterizo requerido de la Orden de Calatrava durante la cruzada granadina; en todo caso, a través de algunas cartas conservadas, parecen quedar sobradamente de manifiesto el afecto y agradecimiento mostrados por Garci López hacia el monarca y la favorable actitud de éste hacia el maestre. De todas formas, dada la importancia considerablemente menor de la encomienda de Alcañiz, Alfonso el Benigno no podía esperar - ni exigirel mismo servicio que hemos observado en los casos del Hospital y Montesa.

En 1329 se produjeron las convocatorias a que ya he hecho referencia y que afectaban a todas las Órdenes enclavadas en la Corona: como hemos visto, en una de ellas se especifica el número de caballos - quince- con los que debía servir el maestre de Calatrava; y, en 1330, no he encontrado huellas de ninguna llamada específica a la encomienda de Alcañiz $^{68}$. En 1331, Garci López debió excusarse, sin que sepamos los motivos, para no acudir a la frontera $y$, a finales de marzo, el rey le dispensaba su servicio ${ }^{69}$. Pero, a raiz del asalto nazarí a Guardamar, el maestre fue de nuevo llamado y, si bien no acudió personalmente, sabemos que dos freires de la orden - Ruy López y F. Rodríguez- hicieron una

\footnotetext{
${ }^{67}$ Véanse, entre otros, F. DE RADES Y ANDRADA, Chronica de las tres órdenes y cavallerias de Sanctiago, Calatrava y' Alcántara. Toledo, 1572 [reimp., con un estudio introductorio de D. W. Lomax, en Barcelona, 1980], fols. 48r.-52v.; J. CaRuANA GómEZ DE BARREDA, La orden de Calatrava en Alcañiz, "Teruel", VIII (1952), pp. 106-108; y J. F. O'Callaghan, The Affiliation of the Order of Calatrava with the Order of Citeaux, en The Spanish Military Order of Calatrava and its Affiliates, London, 1975, I, pp. 256-261. Por su emplazamiento geográfico y las circunstancias que acabamos de resumir, la encomienda de Alcañiz constituyó una pieza de primer orden en las relaciones políticas de Castilla con la Corona catalanoaragonesa desde principios del s. XIV; así, LUTTRELL, La Corona de Aragón y' las órdenes militares durante el s.XIV, "VIII Congreso de Historia de la Corona de Aragón", II, vol.II, Valencia, 1970, p.73 alude al considerable punto de fricción que supondrían las posesiones aragonesas de Santiago y Calatrava al comenzar la guerra contra Castilla en 1356.

${ }^{68} \mathrm{C}$, Cr. Alfons III, n” 2147 y reg. 539, fols. 38r.-40r. y 50r. El 21 de agosto de 1330, el monarca y su esposa Leonor concedieron a Alcañiz una serie de privilegios y le confirmaron la ayuda que prestarían siempre a Garci López frente a su oponente en Castilla Juan Núñez: "en toda vuestra vida vos aiudaremos por todo nuestro poder en mantenervos en vuestra honra e stado que agora sodes e que en toda vuestra vida non vos faremos ni vos lexaremos fazer tuerto ni fuerça alguna en los lugares e bienes que agora tenedes ho possedades en nuestros regnos e senyorios, ante por todo nuestro poder vos deffendremos entre todas personas del mundo e faremos quanto podremos que los lugares que don Juan Munyos tiene forçados de la comienda de Çorita sean rendidos e liurados a vos"; C, reg. 481, fol. 262r.

${ }^{69} \mathrm{C}$, reg. 541 , fol. $171 \mathrm{r}$.
} 
incursión, probablemente a mediados de noviembre, por el rio Almanzora, cobrando botín de cautivos y ganado ${ }^{70}$.

A principios de 1332, la nueva convocatoria regia fue soslayada por el anciano Garci López aduciendo una dolencia de piernas que le impedía subir a caballo y su excusa fue nuevamente aceptada por el monarca, que le dispensaba de servir a él y a sus freires ${ }^{71}$. A finales de mayo, era el propio maestre quien se interesaba por la salud del monarca y le ofrecía sus servicios, una vez curada su dolencia ${ }^{72}$. Si traigo a colación estos documentos puramente anecdóticos es porque considero que, más allá de la retórica usual, constituyen una prueba muy expresiva de la especial relación de Garci López con Alfonso el Benigno. Más adelante, se volvió a poner de manifiesto la cordialidad - fruto de la mutua colaboración- que presidía las relaciones del maestre con el monarca: a mediados de junio de 1333, éste daba las gracias a Garci López por haber hecho prender a un tonsurado que había criticado abierta y públicamente al rey, a la reina y al infante Fernando a causa de las donaciones hechas por el Benigno a su esposa e hijo ${ }^{73}$.

\footnotetext{
${ }^{71} \mathrm{C}, \mathrm{Cr}$. Alfons III, n" 3414. Avistados por un importante grupo armado dirigido por el caudillo musulmán de Vera, los freires calatravos regresaron a territorio murciano por la rambla de Nogalte. En la carta enviada al rey, los freires pedían el rápido envio de compañías con caballos y se hacían eco de la angustiosa escasez de combatientes y recursos.

${ }^{71} \mathrm{C}$. Cr. Alfons III. n" 3133 y reg. 534. fol. 59v. Decía Garci López que estaba "muy mal de los pies e de las piernas de gran dollor que tengo en ellos e non puedo cavalgar sy non con grant affán e asy. sennor, por esta razón yo non podría yr a vos syn grant dano de mi cuerpo"; le pedía que le dispensase el servicio pero. si éste era inexcusable, iría aunque fuese "en un açemilla entre dos cabeçales". Otro detalle de la diferente actitud del rey hacia la encomienda de Alcañiz lo encontramos a raiz de producirse las amenazas de ocupación de los bienes de la Orden hospitalaria; en una nota del registro donde se contienen las instrucciones para proceder a las requisiciones puede leerse: "mandavit etiam ut non scriberetur similiter ffratri Garsie Luppi, magistro Calatrave. ex quibusdam causis quo fecit mandatum Bernardo de Podio oretenus": C, reg. 541 . fol. $194 \mathrm{r}$.

${ }^{72} \mathrm{C}, \mathrm{Cr}$. Alfons III, n" 3346. Garci López decía al rey: "nos dixeron commo fuérades un poco flaco. de la qual cosa sabe Dios que nos pesó muy de coraçón e vimos muy mal dia en ello, pero, sennor, que ovimos remedio desque agora nos dixeron que vos yva mejor e sea bendicho el nombre de Dios por ello"; y. más adelante: "e. sennor, loado sea a Dios. bien sano somos ya para sobir en un cavallo e vos yr servir do vos mandardes".

${ }^{73 . " . . . Q u a n t o ~ a ~ l o ~ q u e ~ n o s ~ f i z i e s t e s ~ s a b e r ~ d e l ~ c o r o n a d o ~ d e ~ a q u i ~ q u e ~ s e ~ a t r e v[i o ́] ~ d e z i r ~}$ trayciones contra nos e la reyna e $\cdot 1$ infante don Fferrando...en razón de la(s) donaciones que fiziemos a la reyna e al dito infante, el qual coronado fiziestes prender,...el qual queremos e vos rogamos que castiguedes por tal manera que ell ni los otros nescios no se atrevan de dezir atales locuras e que ... a vos pesa oyr tales cosas contra nos e los nuestros" (C, reg. 534, fols. 14lr.-v.). Creo que se expresa muy bien aquí el estado de opinión ante las desorbitantes $-y$ preñadas de consecuencias- donaciones hechas por el Benigno a su segunda esposa y al hijo habido con ella.
} 
En 1333, Garci López debía estar ya exento de servir personalmente en la frontera pues, a mediados de junio, sólo se exigía que enviase una compañía de caballos y no su presencia física ${ }^{74}$. Y, ya en 1334 , referente a Calatrava sólo he localizado las dos convocatorias que recibieron globalmente todas las Órdenes de la Corona - una, a finales de enero, y otra, a mediados de marzo - sin que pueda añadir nada más acerca de su presunta participación.

\section{C) La Orden de Santiago (encomienda de Montalbán)}

A lo largo de la cruzada contra el reino nazarí, la encomienda santiaguista de Montalbán recibió de Alfonso el Benigno casi el mismo trato de excepción que obtuvo la encomienda calatraveña de Alcañiz, aunque por distintos motivos. Si esta última fue objeto de ciertos favores y de una protección constante por su posición de cabeza de puente frente a Castilla y por el interés del monarca en mantener bajo su obediencia al maestre "cismático", la encomienda de Montalbán quizás lo fuese por la cualidad de quien estaba a su frente: Vidal de Vilanova, una de las personalidades más destacadas de la vida política catalanoaragonesa en el paso del s. XIII al $\mathrm{XIV}^{75}$.

En 1329, Vidal de Vilanova recibió las cuatro cartas de convocatoria que el monarca envió a todas las Órdenes de la Corona, sin que tengamos constancia de la realización del servicio ${ }^{76}$. Como hemos visto más arriba, los freires de todas las Órdenes debieron ser convocados para acudir a la frontera en la primavera-verano de 1330; Vilanova estaba obligado a servir con 10 caballos pero, en junio de ese año, el rey redujo este número a cinco

\footnotetext{
${ }^{74}$ C, reg. 539, fol. 99v.

${ }^{75}$ Véase la semblanza biográfica de este "consumado maestro de la diplomacia aragonesa" (J. Vincke) en R. SÁInZ dE LA MAZA, La Orden de Santiago en la Corona de Aragón (II). La encomienda de Montalbain bajo Vidal de Vilanova (1327-1357), Zaragoza, 1988. pp. 41-43. En general, la participación de Vilanova en la proyectada expedición granadina es ampliamente tratada por esta autora: en consecuencia, me limitaré aquí a resumir y contextualizar sus datos.

${ }^{76}$ En la de finales de julio. el servicio del comendador estaba fijado en 20 caballos: C. reg. 539, fol. 39v. (cf. SÁINZ DE LA MAZA, op. cit., p. 60, nota 5). En el caso de esta encomienda, tal y cono sucedia con Montesa y Alcañiz, tampoco se incluia en el texto de la convocatoria la cláusula conminatoria que figura invariablemente en las cartas dirigidas a los hospitalarios.
} 
$y$, dos meses más tarde, también fue dispensado de esta exigua comitiva ${ }^{77}$. Así, mientras el prior de Cataluña y el maestre de Montesa protagonizaban la algara fronteriza que más arriba hemos evocado, el comendador de Montalbán quedó relevado de su servicio en 1330.

Como sabemos, a lo largo del otoño de 1330, el Benigno se preparaba aparatosamente para entrar en la frontera en la primavera del próximo año. Vidal de Vilanova mostró su disposición a acompañarle en la gran cruzada prevista, pero aprovechó la ocasión para solicitar -y obtener del monarca - el permiso para contraer préstamos garantizados sobre los ingresos de ciertos lugares de la encomienda ${ }^{78}$. Durante 1331, el comendador recibió, como el resto de las Órdenes, una llamada en primavera y dos en otoño, tras el asalto nazarí a Guardamar; aunque, como hemos visto, el servicio de los freires fue finalmente aplazado hasta el 1 de marzo de 1332, la presentación de Vilanova en Orihuela fue demorada por el rey, a petición de los consellers de Barcelona, hasta la primera semana de abril ${ }^{79}$. Sin embargo, pese a todas estas exenciones y concesiones de permisos y moratorias, que, en definitiva, subrayan la relevancia del personaje colocado a su frente, la encomienda santiaguista no se vió libre de las conmutaciones del servicio militar por una cantidad de dinero, decretada por el rey en la primavera de 1332: si Vilanova no se presentaba en Orihuela a principios de abril, se pagaría el estipendio de 20 caballos con las rentas de la encomien$\mathrm{da}^{80}$. Y así fue: dias después, el comendador fue dispensado del servicio siempre que, antes de abril, depositase en poder del obispo de Valencia la suma de $10.000 \mathrm{~s}$. reales ${ }^{81}$. A la luz de la documentación conservada, queda patente que, aún en este caso, la conmutación de la prestación militar

\footnotetext{
${ }^{77} \mathrm{C}$, reg. 541 , fols. 57v. y 61v. (cf. SAINZ DE LA MAZA. op. cit., p. 61, nota 7). La causa de la gracia resulta evidente en el propio preámbulo del primer documento: ". . volentes ergo vos favorabiliter nos habere..."

${ }^{78}$ El rey le autorizaba a pedir un crédito de hasta $40.000 \mathrm{~s}$. reales asignados sobre las rentas de Museros. Anna, La Vila Joiosa, Orxeta, Palau d Anglesola. Sidamon y otros enclaves de la encomienda: C, reg. 541. fol. 72r. (çf. SÁINZ DE LA MAZA. op. cit.. p. 61 y doc. 56 del apéndice).

${ }^{79} \mathrm{C}$, reg. 541, fol. 189r. (cf. SÁlnz dE LA MAZA, op. cit., p. 62, nota 16 y doc. 61 del apéndice).

${ }^{811}$ C. reg. 541. fols. 191v. y 193r. (cf. Sáinz dE LA MAZA, op. (it. p. 62, nota 16). Se daban las instrucciones oportunas a Jaume de Xèrica, encargado - ya lo sabemos- de conducir el ejército pagado con el dinero de las Órdenes.

${ }^{81}$ ACA. C, reg. 541. fols. 195v. y 196r. (cf. SÁINZ DE LA MAZA. (p). cit. p. 63, nota 17 y doc. 63 del apéndice).
} 
de la encomienda de Montalbán se realizó en términos relativamente amigables (valga la expresión), sin las estridencias y escalada de amenazas que hemos observado respecto a la Orden hospitalaria. El pago de los 10.000 sr. al obispo de Valencia fue la causa, en parte, del arrendamiento por tres años de las rentas de Museros al cambista valenciano Jaume Feliu y al notario Jaume Ripoll ${ }^{82}$.

Durante los años 1333 y 1334, sólo tenemos constancia de la inclusión de la encomienda en las cuatro convocatorias generales - dos en 1333 y otras dos en el año siguiente-, pero no de la plasmación efectiva de su servicio en la frontera.

\section{CONSIDERACIONES FINALES}

Creo que, por lo que respecta al Hospital, su actitud durante el largo lustro que duró la guerra abierta contra Granada puede servir de excelente test para medir el grado de conflictividad de la Orden con la monarquía. Se ha dicho repetidamente que las relaciones entre una y otra experimentaron un sensible cambio a partir del reinado de Jaime II; como afirma Luttrell, durante la primera mitad del s.XIV, después de la caída de Tierra Santa y de la conclusión de la reconquista catalanoaragonesa, los hospitalarios continuaron pagando dinero y servicios a la Orden, pero la Corona, en perpetuo conflicto con el maestre de Rodas y con el papa, luchó denodadamente por controlar tales recursos ${ }^{83}$. En última instancia, ese cambio en las relaciones tiene que ver con el importante y progresivo incremento patrimonial de la Orden hospitalaria y, al mismo tiempo, con el proceso de afianzamiento del poder regio. Ello se refleja muy claramente en los frecuentes conflictos por cuestiones de soberanía: mientras el maestre de la Orden reivindicaba su autoridad indiscutible sobre los freires, el monarca

\footnotetext{
${ }^{82}$ En el momento de pedir el correspondiente permiso al rey, el comendador aducía como causas para proceder al arrendamiento el pago de cierta cantidad de florines a la cámara apostólica como frutos del primer año y otros pagos al maestre de la Orden; el monarca autorizó el arriendo, pues ello facilitaría la entrega de los $10.000 \mathrm{sr}$. necesarios para la defensa fronteriza; C, reg. 486, fol. 70r. (cf. SÁINZ DE LA MAZA, op. cit., p. 63, nota 18). Sin embargo, esta cantidad tardaría en ser pagada, si alguna vez lo fue: a comienzos de mayo de 1332, el Benigno preguntaba al obispo de Valencia si Vilanova había satisfecho ya los 10.000 sr., que eran muy necesarios en la frontera: C. reg. 499, fol. 36r.

${ }^{83}$ A. LutTREll. The Aragonese Crown. p. 1.
} 
- emperador en su reino- pretendía colocar bajo su exclusiva jurisdicción a las encomiendas enclavadas en territorio catalanoaragonés ${ }^{84}$. Considero que algunos de los datos contenidos en las páginas anteriores constituyen una prueba palmaria del estado crítico de las relaciones entre la Orden y la monarquía en los años de Alfonso el Benigno. En efecto, a las reiteradas resistencias de algunos comendadores a realizar el servicio exigido (manifestadas en la lisa y llana negativa a acudir a la frontera, en el abandono de la misma sin autorización real o en el envío de una escasa comitiva de combatientes), el rey respondió con una escalada de presiones que fueron desde el secuestro de las responsiones debidas al maestre de Rodas hasta los intentos de formar un ejército pagado con las rentas de las encomiendas. Otra cosa sería saber el grado de eficacia de esas aparentemente duras medidas, si realmente se llegaron a poner en práctica.

Frente al turbulento y bien documentado cuadro que puede esbozarse sobre las relaciones del Hospital con la Corona, algo diferente parece deducirse - a partir de muchas menos evidencias- de la participación del resto de las Órdenes en la cruzada. Por lo que respecta a Montesa, el servicio exigido por el rey parece que fue realizado con mayor o menor puntualidad, pero siempre de manera efectiva: por ello mismo, el Benigno excluyó en todo momento a los freires montesanos de las severas medidas adoptadas contra los hospitalarios. En cuanto a la encomienda calatraveña de Alcañiz, da la impresión de que ni el monarca puso demasiado interés en exigir su servicio ni el maestre (reconocido como tal sólo por el Benigno, no lo olvidemos) se preocupó en realizarlo; sus frecuentes excusas fueron aceptadas de buen grado por el rey, al tiempo que confirmaba y aumentaba los privilegios de Alcañiz. Algo parecido sucedió con la encomienda santiaguista de Montalbán: después de diversas exenciones y moratorias concedidas a Vidal de Vilanova, el servicio militar fue conmutado por dinero, tal y como había sucedido con algunas encomiendas de la castellanía de Amposta.

Dado su específico carácter, la documentación que aquí he utilizado no es la más adecuada para dar cuenta de la presencia efectiva de los freires en la frontera ni permite, por tanto, medir el grado exacto del cumplimiento del servicio exigido en cada momento por el Benigno. A partir de algunos datos incidentales, quizás podamos concluir prudentemente que tres o cuatro

\footnotetext{
${ }^{84}$ M. BONET. La Orden del Hospital en la Corona de Aragón. pp. 59-67.
} 
comendadores de la castellanía estaban en Orihuela en agosto de 1329; que la presencia del prior Arnau d'Alós está atestiguada en las regiones fronterizas a finales de agosto de 1330 y de nuevo a finales de 1331 y parte de 1332; que el lugarteniente de la castellanía G. de Guimerà está documentado en Alicante hacia mediados de mayo de 1332 y que, un año después, el comendador de Monzón se había limitado a enviar a la frontera la exigua comitiva de tres caballos. Por lo que respecta a Montesa, su maestre Pere de Tous participó en la algara de finales de agosto de 1330 y lo encontramos en la zona fronteriza en el otoño de 1331 y otra vez en el verano de 1332, mientras su lugarteniente B. de Montsonís está documentado en la primavera de este último año. Por fin, hemos visto que dos freires calatravos hicieron una entrada en territorio nazarí en noviembre de 1331, desde donde lamentaban la falta de medios para combatir eficazmente a los granadinos. Un síntoma más, entre centenares, de las dificultades con que tropezó el Benigno para plasmar sus irreales sueños de cruzada en el contexto preciso del primer tercio del s.XIV catalanoaragonés.

\section{RÉSUMÉ}

L'objectif de cet article est celui d'observer la participation de quatre des Ordres Militaires de la Couronne d'Aragon à la Croisade organisée par Alphonse le Bénin contre le royaume nasride de Grenade, entre 1329 et 1334. Une fois étudiée en détail l'attitude de l'Ordre de Saint-Jean pendant l'expédition militaire, grâce à l'abondante documentation conservée, on observe d'une manière plus superficielle -étant donnée la manque de sources et de bibliographie- la participation des Ordres de Montesa, Calatrava et Santiago. Par rapport aux résistances des Hospitaliers à faire son service militaire et à la prise des mesures énergiques de la part du roi contre l'Ordre, on constate l'accomplissement ponctuel du service demandé à l'Ordre de Montesa; par contre, on n'a pas pu verifier avec précision la participation des Ordres de Calatrava et Santiago à la Croisade.

\section{SUMMARY}

This article is devoted to the study of the participation of four catalano-aragonese Military Orders in the Crusade organized by king Alphonse the Benign of Aragon against the Nasri kingdom of Grenade, between 1329 and 1334.

On the basis of a not very large number of records, the author analyzes attentively the role of the Hospitallers during the enterprise; however - because of the lack of records-, the role played by the Orders of Montesa, Calatrava and Santiago has been studied with less detail. 
Whereas the Hospitallers opposed resistance to the performance of military service - which forced the sovereign to adopt harsh measures against them-, the Montesa knights fulfilled their duties better, and the rest of the Orders were absent from the Frontier. 